\title{
Unanticipated Stereoselectivity in the Reaction of Primaquine $\alpha$-Aminoamides with Substituted Benzaldehydes: A Computational and Experimental Study ${ }^{\dagger}$
}

\author{
Ricardo Ferraz, ${ }^{\ddagger}, \S$ José R. B. Gomes,,${ }^{\ddagger}$ Eliandre de Oliveira," Rui Moreira, ${ }^{\perp}$ and \\ Paula Gomes*,: \\ Centro de Investigação em Química (UP), Departamento de Química, Faculdade de Ciências, \\ Universidade do Porto, Rua Campo Alegre, 687, P-4169-007 Porto, Portugal, Escola Superior de \\ Tecnologias de Saúde do Porto, Instituto Politécnico do Porto, Rua João Oliveira Ramos, 87, \\ P-4000-294 Porto, Portugal, Plataforma de Proteòmica, Parc Cientific de Barcelona, Universitat de \\ Barcelona, Carrer Josep Samitier, 1-5, E-08028 Barcelona, Spain, and Centro de Estudos de Ciências \\ Farmacêuticas, Faculdade de Farmácia, Universidade de Lisboa, Avenida Professor Gama Pinto, \\ P-1649-003 Lisboa, Portugal \\ pgomes@fc.up.pt
}

Received February 15, 2007

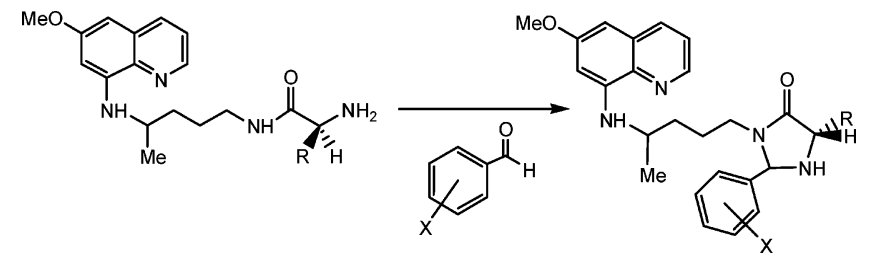

Imidazolidin-4-ones are commonly employed as skeletal modifications in bioactive oligopeptides, either as proline surrogates or for protection of the $N$-terminal amino acid against aminopeptidase- and endopeptidase-catalyzed hydrolysis. Imidazolidin-4-one synthesis usually involves the reaction of an $\alpha$-aminoamide moiety with a ketone or an aldehyde to yield an imine, followed by intramolecular cyclization. We have unexpectedly found that imidazolidin-4-one formation is stereoselective when benzaldehydes containing $o$-carboxyl or $o$-methoxycarbonyl substituents are reacted with $\alpha$-aminoamide derivatives of the antimalarial drug primaquine. A systematic computational and experimental study on the stereoselectivity of imidazolidin-4-one formation from primaquine $\alpha$-aminoamides and various substituted benzaldehydes has been carried out, and they have allowed us to conclude that intramolecular hydrogen-bonds involving the $\mathrm{C}=\mathrm{O}$ oxygen of the $o$-substituent play a crucial role.

\section{Introduction}

Imidazolidin-4-one formation was introduced as a useful prodrug approach to protect the $N$-terminal amino acid residue of di-, tri-, and pentapeptides against aminopeptidase- and endopeptidase-catalyzed hydrolysis. ${ }^{1-4}$ The general synthetic approach for the preparation of imidazolidin-4-ones involves the acid- or base-catalyzed reaction of the peptide with a ketone

$\dagger$ Dedicated to Professor Carlos M. M. S. Corrêa, Professor Emeritus of the University of Porto.

¥ Centro de Investigação em Química.

$\S$ Escola Superior de Tecnologias de Saúde do Porto.

" Plataforma de Proteòmica.

${ }^{\perp}$ Centro de Estudos de Ciências Farmacêuticas.

(1) Klixbull, U.; Bundgaard, H. Int. J. Pharm. 1984, 20, 273.

(2) Rasmussen, G. J.; Bundgaard, H. Int. J. Pharm. 1991, 71, 45.

(3) Rasmussen, G. J.; Bundgaard, H. Int. J. Pharm. 1991, 76, 113.

(4) Bak, A.; Fich, M.; Larsen, B. D.; Frokjaer, S.; Friis, G. J. Eur. J. Pharm. Sci. 1999, 7, 317. or an aldehyde, followed by an intramolecular cyclization. Peptide imidazolidin-4-one derivatives were reported to be quantitatively hydrolyzed to the parent peptide in physiological conditions ( $\mathrm{pH} 7.4$ buffer at $37^{\circ} \mathrm{C}$ ) with half-lives ranging from 1 to $30 \mathrm{~h}$, which was dependent on the $N$-terminal dipeptide sequence and on the imidazolidinone ring substituents. ${ }^{1-4}$

We have been working on potential peptidase-stable derivatives of the antimalarial primaquine by performing acylation of its primary amino group with an amino acid to yield $\alpha$-aminoamides, $\mathbf{1}$, which are then converted to imidazolidin4-ones, 2 , by reaction with a ketone or an aldehyde. ${ }^{5-7}$ When the aldehyde moiety corresponds to $o$-formylbenzoic acid

(5) Gomes, P.; Araújo, M. J.; Rodrigues, M.; Vale, N.; Azevedo, Z.; Iley, J.; Chambel, P.; Morais, J.; Moreira, R. Tetrahedron 2004, 60, 5551.

(6) Araújo, M. J.; Bom, J.; Capela, R.; Casimiro, C.; Chambel, P.; Gomes, P.; Iley, J.; Lopes, F.; Morais, J.; Moreira, R.; de Oliveira, E.; do Rosário, V.; Vale, N. J. Med. Chem. 2005, 48, 888. 
$(o \mathrm{FbzOH})$, an additional cyclization occurs, and $1 H$-imidazo[2,1-a]isoindole-2,5(3H,9bH)-diones, $\mathbf{3}$, are produced. Using the commercially available $( \pm)$-primaquine and enantiomerically pure L-amino acid as building blocks for compounds $\mathbf{1}$, these are obtained as 1:1 mixtures of two diastereomers. Thus, the reaction of $\mathbf{1}$ with aldehydes is expected to yield $\mathbf{2}$ as equimolar mixtures of the four possible diastereomers.

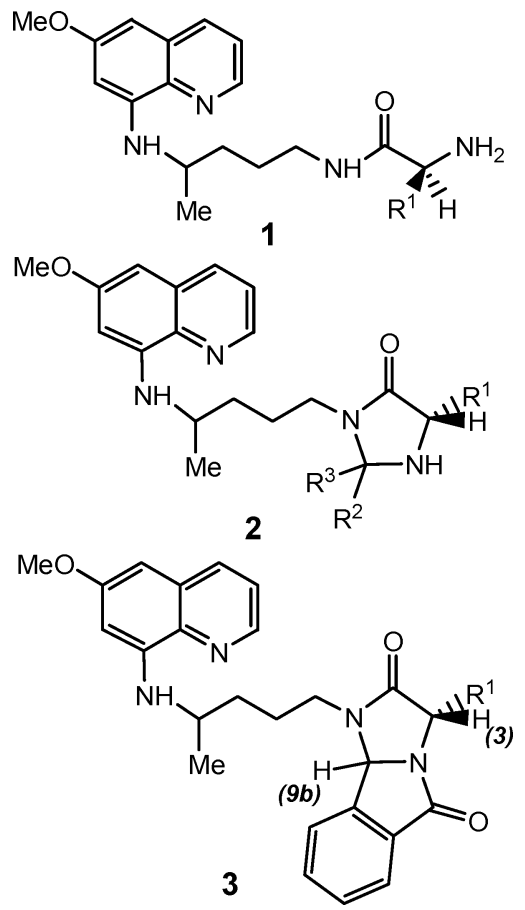

We have previously observed that this was the case when $m, p$-dimethoxybenzaldehyde (veratraldehyde) was used, whereas the reaction of $\mathbf{1}$ with $o \mathrm{FBzOH}$ produced only two diastereomers of compounds $\mathbf{3}$, which indicated that the intermediate formation of the imidazolidin-4-one ring was stereoselective. ${ }^{5}$ Considering the generally accepted mechanism of imidazolidin-4-one formation via an imine intermediate, ${ }^{8}$ we hypothesized that stereoselectivity could be due to a constrained conformation of the imine prior to the imidazolidin-4-one ring-closure. ${ }^{5}$ This constraint was ascribed to intramolecular hydrogen-bonds that involve the oxygen of the ortho $\mathrm{C}=\mathrm{O}$ group in $o \mathrm{FBzOH}$, on the basis of computational geometry optimization of the imine formed from $o \mathrm{FBzOH}$ and $\mathrm{N}$-alanilprimaquine. ${ }^{5}$ Thus, understanding the reason for this unexpected stereoselectivity is fundamental to explore the molecular mechanisms of imidazolidin-4-one formation and to the future tuning of imidazolidin4-one stereochemistry, because imidazolidin-4-ones have potential biological interest beyond the development of peptide prodrugs. ${ }^{5-7,9-12}$ To analyze the effect of substituents on the

(7) Chambel, P.; Capela, R.; Lopes, F.; Iley, J.; Morais, J.; Gouveia, L.; Gomes, J. R. B.; Gomes, P.; Moreira, R. Tetrahedron 2006, 62, 9883.

(8) Heck, A. J. R.; Bonnici, P. J.; Breukink, E.; Morris, D.; Wills, M. Chem.-Eur. J 2001, 7, 910.

(9) Pinza, M.; Farina, C.; Cerri, A.; Pfeiffer, U.; Riccaboni, M. T.; Banfi, S.; Biagetti, R.; Pozzi, O.; Magnani, M.; Dorigotti, L. J. Med. Chem. 1993 , 36,4214 .

(10) Pinza, M.; Riccaboni, M. T.; Cerri, A.; Farina, C. Eur. Pat. Appl. EP 335483 A2, 1989. Chem. Abstr. 1990, 112, 158246.

(11) Farina, C.; Gagliardi, S.; Parini, C.; Martinelli, M.; Ghelardini, C. PCT Int. Appl. WO 2004085438 A2, 2004; Chem. Abstr. 2004, 141, 332191.

(12) Satoh, A.; Kato, T.; Ooi, N.; Iwasawa, Y. PCT Int. Appl. WO 2001096337 A1; Chem. Abstr. 2001, 136, 37608. stereochemical outcome of imidazolidin-4-one formation, primaquine $\alpha$-aminoamides (1) were reacted with eight differently substituted benzaldehydes (Scheme 1). We focused our attention on the number of product $(\mathbf{5}$, Scheme 1$)$ diastereomers that were formed in each case. The benzaldehydes were chosen to include seven different ortho-substituents $(o-\mathrm{Me}, o-\mathrm{OH}, o$-COOMe, $o$-COMe, $o$-OMe, $o-\mathrm{CF}_{3}$, and $o-\mathrm{NO}_{2}$ ) that present a wide range of electronic properties ( $\sigma_{\text {ortho }}$ values ranging from 0.07 to 1.99 ) and hydrogen-bond acceptor abilities, as well as one parasubstituent ( $p$-COOMe). Computational studies on the geometries of the imine intermediates $\mathbf{4}$ formed by the reaction of 1d with benzaldehydes (cf. Scheme 1) were also carried out at the DFT level, and this theoretical approach further included four other ortho-substituted benzaldeydes $\left(o-\mathrm{CH}_{2} \mathrm{NH}_{2}, o-\mathrm{CH}_{2}-\right.$ $\mathrm{OH}, o$-CSMe, and $o$-CSOMe) that were either commercially unavailable or were unsuitable for experimental work. The results herein presented provide a more complete understanding of the origin of the relative stereoselectivity in imidazolidin-4one (5) formation.

\section{Results and Discussion}

Synthesis and Structural Analysis of 5. Compounds 5a-c were prepared by reacting $N$-acylprimaquines $1 \mathbf{a}-\mathbf{c}$ with methyl 2 -formylbenzoate ( $o \mathrm{FBzMe}$ ), as is depicted in Scheme 1. TLC monitoring of each of these reactions allowed for the detection of two products, which were isolated by column chromatography on silica and were characterized by MALDI-TOF MS and NMR. In all cases, the main product (ca. $40 \%$ average yield, data not shown) corresponded to the imidazo[2,1-a]isoindole-2,5-diones $3 \mathbf{a}-\mathbf{c}\left(1: 1\right.$ mixture of two diastereomers) previously described. ${ }^{5}$ These were formed by an intramolecular nucleophilic attack of the imidazolidin-4-one $\mathrm{NH}$ to the ester carbonyl, with methanol as the leaving group (Scheme 2). The minor products that were isolated from these reaction mixtures presented molecular weights that are compatible with the structures of $\mathbf{5 a}-\mathbf{c}$, which were further confirmed by NMR. It could be argued that the formation of $\mathbf{3 a}-\mathbf{c}$ might arise from the reaction of $\mathbf{1 a}-\mathbf{c}$ with the $o \mathrm{FBzOH}$ that is present as either a contaminant or as an ester cleavage product of oFBzMe. However, because (i) $o$ FBzMe was freshly prepared in our laboratory and was checked for any detectable trace of impurities, and (ii) solvolysis of ester $o$ FBzMe under the reaction conditions employed (anhydrous methanol) would not yield $o \mathrm{FBzOH}$, the above arguments fail to explain the obtention of $\mathbf{3 a}-\mathbf{c}$ as main products. Most likely, $\mathbf{5 a}-\mathbf{c}$ were first formed and then underwent an intramolecular attack of the imidazolidinone $\mathrm{N}^{1}$ over the ester carbonyl, with departure of methanol. This process further supports previous assumptions that $\mathbf{5 a}-\mathbf{c}$ are intermediates for the final products $\mathbf{3 a}-\mathbf{c}^{5}$

NMR spectra showed that, in all cases, $\mathbf{5 a}-\mathbf{c}$ were isolated as chromatographically homogeneous fractions that correspond to 1:1 mixtures of two coeluting diastereomers. Thus, ${ }^{1} \mathrm{H}$ NMR data $(300 \mathrm{MHz})$ show that resonances of the NCHN protons ( $\mathrm{H}-2$ of the imidazolidinone ring) appear as two 1:1 singlets at 6.0-6.3 ppm. The same is consistently observed for the resonances of $\mathrm{COOCH}_{3}$, quinoline $\mathrm{H}-5$, and primaquine $\mathrm{CH}_{3}$ protons. ${ }^{13} \mathrm{C}$ NMR spectra presented peak duplication for, among others (cf. Scheme 3 for atom labeling), the Q-2, Q-8, and Q-9 quinoline carbons; the PQ-1, PQ-2, PQ-3, and PQ-4 primaquine aliphatic carbons; the imidazolidinone carbon I-2; and the Ar-1 and Ar-2 carbons of the $o$-methoxycarbonylphenyl substituent.

Bidimensional NMR ${ }^{1} \mathrm{H} /{ }^{1} \mathrm{H}$ (COSY, TOCSY, and NOESY) and ${ }^{1} \mathrm{H} /{ }^{13} \mathrm{C}$ (HMBC and HSQC) correlation experiments were 
SCHEME 1. Synthetic Route to $5^{a}$

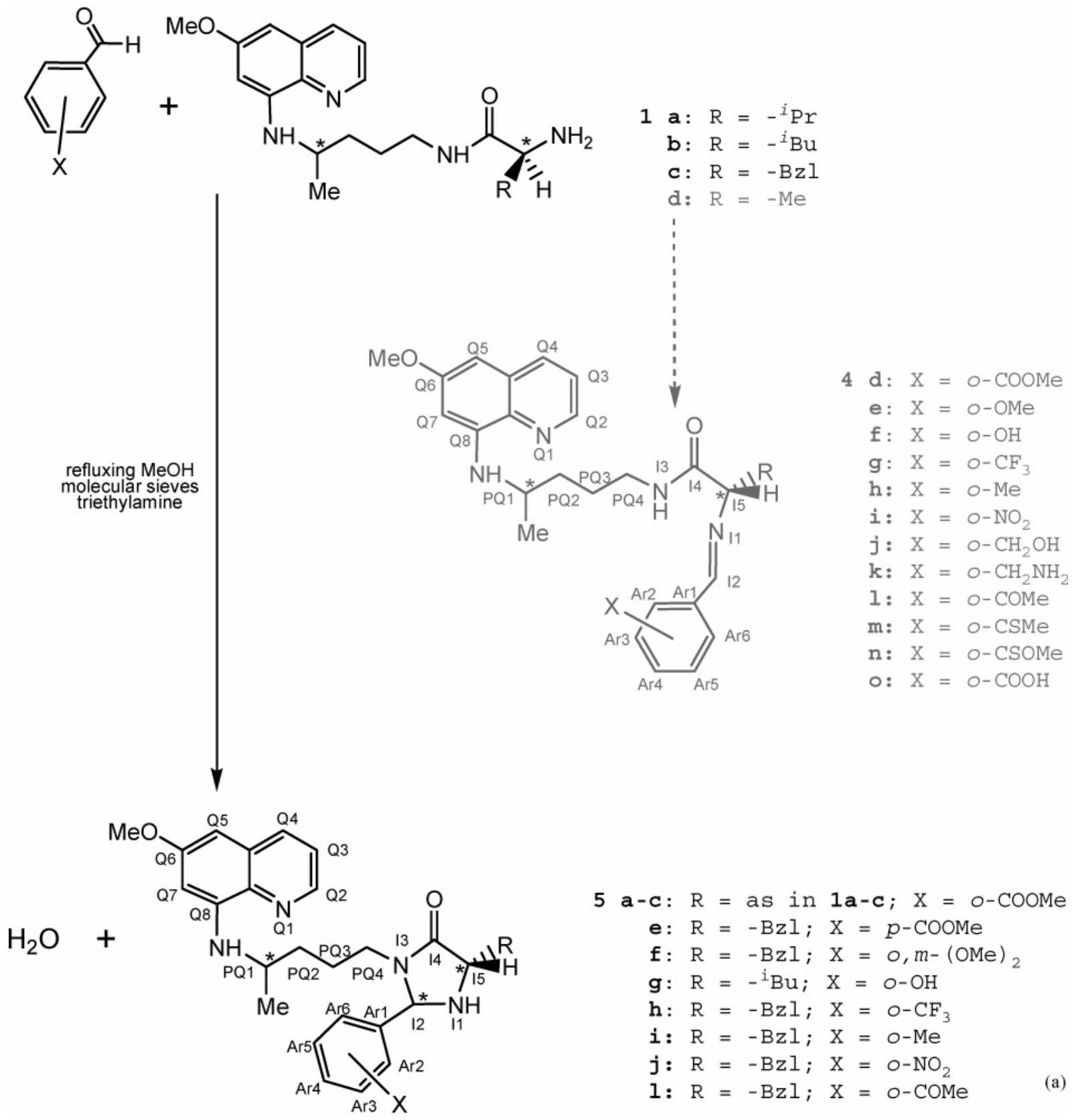

${ }^{a} \mathbf{1 d}$ and $\mathbf{4 d}-\mathbf{o}$ (in gray) were only considered in the computational study.

SCHEME 2. Conversion of $5 a-c$ into $3 a-c$

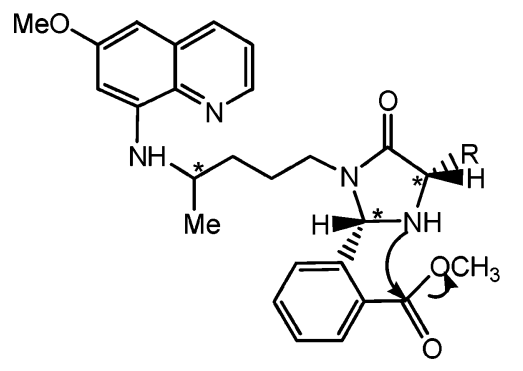

5a-c

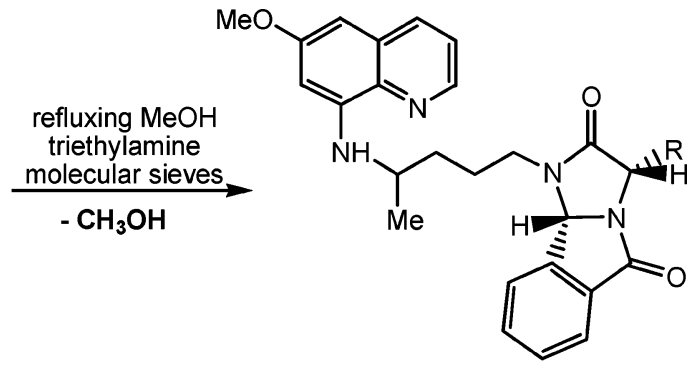

3a-c run for $\mathbf{5 b}$ and $\mathbf{5 c}$ to provide both with an unequivocal assignment of all peaks and further insight into the three dimensional (3D) structure of the compounds. These higher- resolution $(500 \mathrm{MHz}) \mathrm{NMR}$ experiments allowed us to observe that the ${ }^{1} \mathrm{H}$ NMR signal due to the imidazolidinone I-2 proton actually appeared as a pair of $1: 1$ doublets with $J \approx 0.8 \mathrm{~Hz}(\delta$ 


\section{SCHEME 3. Relevant ${ }^{4} J$ (A) and NOEs (B) Observed for} 5c

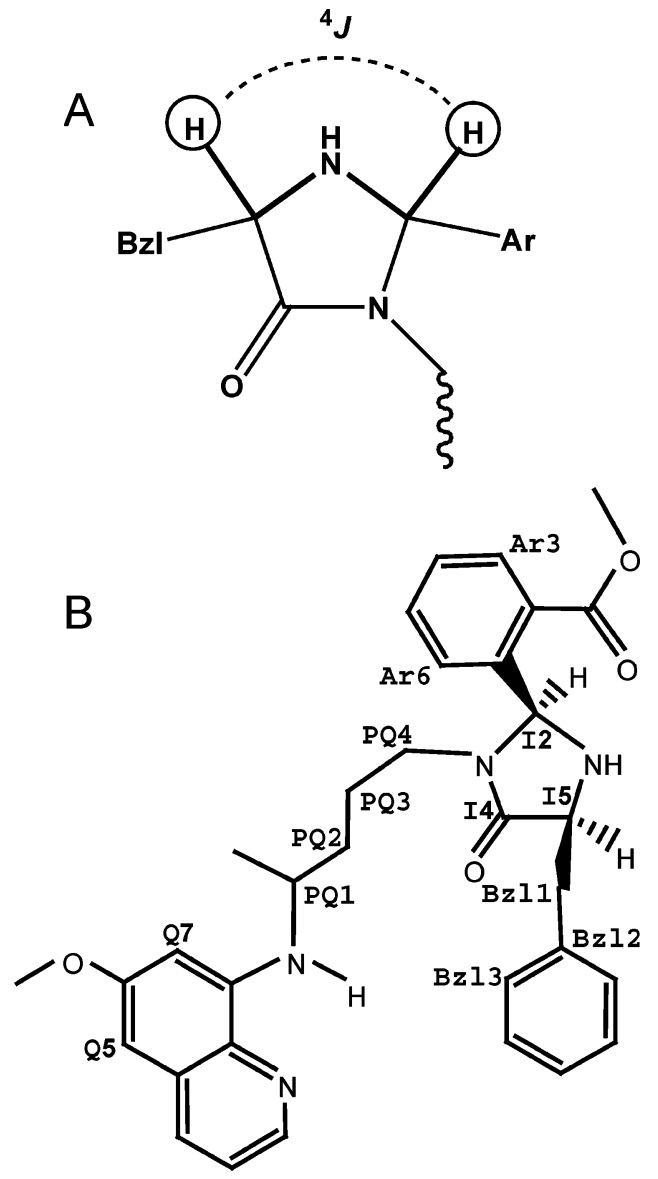

$=6.258$ and $6.237 \mathrm{~Hz}$ for $\mathbf{5 b}, \delta=6.182$ and $6.165 \mathrm{~Hz}$ for $\mathbf{5 c}$ ). Interestingly, these doublets were attributed to a four-bond extended coupling $\left({ }^{4} J_{\mathrm{HH}}\right)$ between the imidazolidinone I- 2 and I-5 protons, as shown by the COSY spectrum. This long-range effect can be attributed to a ${ }^{4} J_{\mathrm{HH}} \mathrm{W}$-coupling that is typical of rigid cyclic structures such as bornanes ${ }^{13}$ and norbornenes, ${ }^{14}$ substituted cyclohexanes and cyclohexanones, ${ }^{15}$ porphyrins, ${ }^{16}$ and other mono- and policyclic compounds ${ }^{17-19}$ where a fixed $\mathrm{W}$-shaped orientation of the four bonds is present. For instance, for heterocycles where the heteroatom $(-\mathrm{O}-,-\mathrm{NH}-)$ is placed in the middle of the W-motif, a ${ }^{4} J_{\mathrm{HH}}$ of up to $7 \mathrm{~Hz}$ can be observed. ${ }^{20}$ Hence, NMR spectroscopy strongly suggests that the imidazolidinone ring conformation is as depicted in Scheme $3 \mathrm{~A}$, that is, with protons I-2 and I-5 adopting a cis configuration relative to each other. This cis configuration of the imidazolidinone protons I-2 and I-5 was further confirmed by the NOESY

(13) Flautt, T. J.; Erman, W. F. J. Am. Chem. Soc. 1963, 85, 3212 (14) Laszlo, P.; von Ragué, Schleyer, P. J. Am. Chem. Soc. 1964, 86, 1171.

(15) Rassat, A.; Jefford, C. W.; Lehn, J. M.; Waegell, B. Tetrahedron Lett. 1964, 5, 233.

(16) Chmielewski, P. J.; Latos-Grażyński, L. J. Chem. Soc. Perkin Trans. 2 1995, 503

(17) Meinwald, J.; Lewis, A. J. Am. Chem. Soc. 1963, 85, 2514.

(18) Osawa, Y.; Neeman, N. J. Am. Chem. Soc. 1963, 85, 2856.

(19) Perry, N. B.; Blunt, J. W.; Munro, M. H. G.; Higa, T.; Sakai, R. J. Org. Chem. 1988, 53, 4127.

(20) Hesse, M.; Meier, H.; Zeeh, B. Spectroscopic Methods in Organic Chemistry; Enders, D., Noyori, R., Trost, B. M., Eds.; Foundations of Organic Chemistry Series, Translated by Linden, A., Murray, M.; Thieme: New York, 1997; pp 110-111. experiments. A strong NOE was observed between those two protons for both $\mathbf{5 b}$ and $\mathbf{5} \mathbf{c}$. Other important NOEs were found, which allowed us to build a probable tridimensional structure for these molecules. For example, the following relevant NOEs were observed for 5c (Scheme 3B): (a) between the imidazolidinone I-2 and the primaquine methylene (PQ-3, PQ-4) protons; (b) between the aromatic protons of the imidazolidinone C-2 substituent (e.g., Ar-6) and the primaquine methylene group PQ-4, as well as with the primaquine $\mathrm{NH}$ group; (c) the primaquine NH group and the benzyl protons Bzl-1 (methylene) and Bzl-3 (aromatic). These NOE correlations, especially (b) and (c), clearly suggest that these compounds adopt a compactly folded structure. This structure will probably be stabilized by intramolecular hydrogen-bonds and by hydrophobic interactions between the quinoline ring and the substituents on the imidazolidinone's positions I-2 and I-5.

The above findings are in agreement with our previous observations for compounds $\mathbf{3}$, which were formed by the reaction of $\mathbf{1}$ with 2 -formylbenzoic acid. ${ }^{5}$ This reaction was equally stereoselective, and spectroscopic data showed that hydrogens 3 and $9 \mathrm{~b}$ (cf. structure $\mathbf{3}$ ) of compounds $\mathbf{3}$ also adopted a cis configuration..$^{5}$ Together, these results allow us to establish, with a considerable degree of confidence, that the new stereocenter that was created upon formation of compounds $\mathbf{5 a}-\mathbf{c}$ adopts the $S$ configuration. Hence, each one of compounds $\mathbf{5 a}-\mathbf{c}$ is obtained as a mixture of diastereomers $2 S, 5 S, 1^{\prime} S$ and $2 S, 5 S, 1^{\prime} R$. These diastereomers differ only at the configuration of the primaquine $\mathrm{PQ}-1$ carbon because racemic primaquine was used as the starting material.

The synthetic approach to compounds $\mathbf{5 e}-\mathbf{l}$ was performed, as depicted in Scheme 1, by reacting $N$-phenylalanilprimaquine (1c) with seven different benzaldehydes: methyl $p$-formylbenzoate, $o$-acetylbenzaldehyde, $o, m$-dimethoxybenzaldehyde, salicylaldehyde, $o$-trifluoromethylbenzaldehyde, $o$-methylbenzaldehyde, and $o$-nitrobenzaldehyde. As mentioned before, the choice of the benzaldehyde substituents was planned to evaluate how both substituent position and stereoelectronic/hydrogenbonding properties could influence the reaction stereoselectivity. TLC monitoring of the reaction between 1c and methyl $p$-formylbenzoate to give $\mathbf{5 e}$ revealed three chromatographically distinct products, all of which presented the expected molecular weight. These three fractions were isolated by column chromatography, and the amount of one of them $\left(\mathbf{5} \mathbf{e}_{\mathbf{1}}\right)$ approximately equaled the sum of the other two $\left(\mathbf{5 e}_{2}\right.$ and $\left.\mathbf{5} \mathbf{e}_{3}\right)$, which is compatible with $\mathbf{5 e}_{\mathbf{1}}$ as a 1:1 mixture of the two chromatographically undistinguishable diastereomers of $\mathbf{5 e}$, whereas $\mathbf{5} \mathbf{e}_{2}$ and $\mathbf{5 e}_{3}$ would be the other two pure diastereomers. NMR analysis of the three fractions confirmed this assumption, as signal duplication was observed in both the ${ }^{1} \mathrm{H}$ and the ${ }^{13} \mathrm{C}$ NMR spectra of $\mathbf{5} \mathbf{e}_{1}$ (similar to that above-described for $\mathbf{5 a}-\mathbf{c}$ ), but it was not observed in the case of $\mathbf{5 e}_{2}$ and $\mathbf{5 e}_{3}$ (detailed spectral data available as Supporting Information). This result, together with that reported for $\mathbf{5 c}$, strongly suggests that stereoselectivity requires the $\mathrm{CO}_{2} \mathrm{Me}$ substituent to be in the ortho position.

The syntheses of compounds $\mathbf{5 f}-\mathbf{i}$ yielded mixtures that contained at least two fractions with the correct molecular weights. These were isolated and were found to be mixtures of diastereomers. Exhaustive chromatographic purifications allowed us to isolate pure diastereomers in some cases (detailed spectral data given as Supporting Information), but no stereoselectivity was detected in any case, as 1:1:1:1 mixtures of the expected four diastereomers were consistently obtained in all 

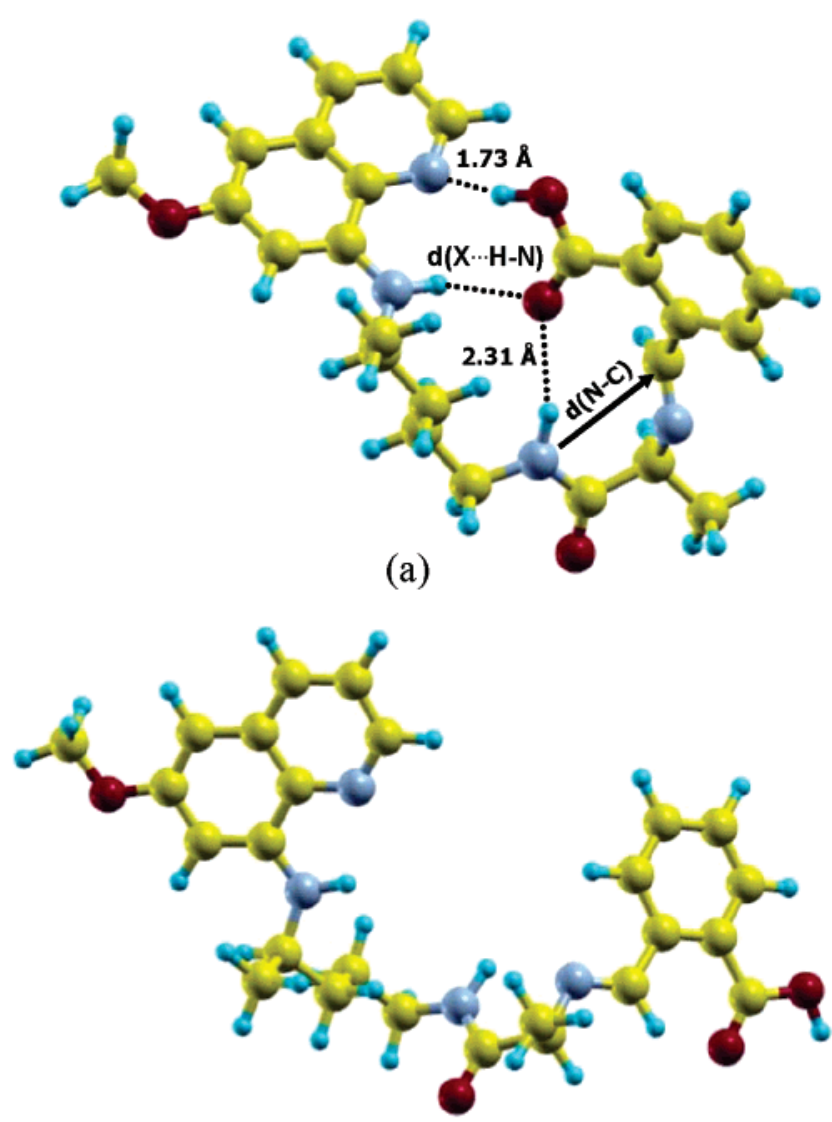

(b)

FIGURE 1. B3LYP/6-31G* optimized structures of the compact inward (a) and open outward (b) structures for the imine intermediate 4o. Internal hydrogen-bonds are identified with dotted lines. More details are given in Table 1.

reactions. The diastereomer ratios were identical for substituents with (e.g., $o, m-\mathrm{OMe}_{2}$ or $o-\mathrm{OH}, \mathbf{5 f}$ and $\mathbf{5 g}$, respectively) or without (e.g., $o-\mathrm{CF}_{3}$ or $o-\mathrm{Me}, \mathbf{5} \mathbf{h}$ and $\mathbf{5 i}$, respectively) hydrogenbond acceptor properties. In the case of $\mathbf{5} \mathbf{j}$, which contains the strongly electron-withdrawing nitro group $\left(\sigma_{\text {ortho }}=1.99\right)$, a very complex mixture was obtained, and product purification was quite difficult. Nevertheless, two fractions enriched in products with the correct molecular weight were isolated and were analyzed by NMR. In this case, four different chemical shifts could be found for the imidazolidin-4-one H-2 proton, which confirmed that all four possible diastereomers of $\mathbf{5} \mathbf{j}$ were also formed. Quite importantly, the $o-\mathrm{NO}_{2}$ group is also coplanar with the benzene ring and contains the oxygen atoms two bonds apart from the aromatic ring, but it gives an opposite stereochemical outcome to that of $o-\mathrm{CO}_{2} \mathrm{H}$ and $o-\mathrm{CO}_{2} \mathrm{Me}$ groups.

Overall, these results strongly suggest that a benzaldehyde containing an ortho-carbonyl substituent is required to achieve stereoselectivity in the synthesis of imidazolidin-4-ones. Further confirmation of this assumption would come from the synthesis of $\mathbf{5 l}$, by the reaction of $\mathbf{1} \mathbf{c}$ with $o$-acetyl-benzaldehyde. Because the aldehyde moiety is usually more reactive than the ketone moiety, this reaction would probably lead to the intermediate imine analogous to $\mathbf{4 m}$ (the amino acid side chain would be benzyl instead of methyl in $\mathbf{4 m}$, Scheme 1). If our hypothesis was true, then only two diastereomers of $\mathbf{5 l}$ would be formed. However, despite the use of several experimental approaches to obtain a tractable reaction mixture, all syntheses led to rather complex mixtures from which a pure product could not be isolated. Those mixtures were repeatedly separated by column chromatography and analyzed by MALDI-TOF MS, but the expected molecular weight was not detected in any of the collected fractions, even when significantly enriched in a given reaction product.

Computational Analysis of Imines $4 \mathbf{4}-\mathbf{o}$. To gain further insight into the structural factors that may dictate whether ringclosure in the formation of imidazolidin-4-ones is stereoselective or not, DFT calculations at the B3LYP/6-31G* level of theory have been carried out.

In a first stage, the molecular structure of an inward conformation of $\mathbf{4}$ where $\mathrm{R}=-\mathrm{CO}_{2} \mathrm{H}$, which was already optimized in a previous work, was further optimized at the DFT level considered here and is depicted in Figure 1a. This compact structure, with three short $\mathrm{O}-\mathrm{H} \cdot \cdots \mathrm{N}$ or $\mathrm{N}-\mathrm{H} \cdot \cdots \mathrm{O}$ bonds, $d(\mathrm{X} \cdots \mathrm{H}-\mathrm{N})$ appears in Table 1 , is significantly more stable, by $34.2 \mathrm{~kJ} / \mathrm{mol}$, than the open structure illustrated in Figure $1 \mathrm{~b}$. In the inward structure of the imine intermediate, the distance between the amide nitrogen and the imine carbon is indeed very small, $d\left(\mathrm{~N}-\mathrm{C}_{2}\right)=3.234 \AA$. Thus, the imine intermediate adopts a rigid quasi-cyclic structure, which suggests that ring-closure will promptly occur to yield only one out of two possible configurations: I-2 and I-5 hydrogens cis-positioned relative to each other.

Because the experimental evidence suggests that the interaction between the $\mathrm{C}=\mathrm{O}$ oxygen atom of the $o-\mathrm{CO}_{2} \mathrm{H}$ substituent and the amide group of $\alpha$-aminoamide moiety is responsible for the stereoselectivity observed, the importance of that interaction in the imine intermediate 40 was assessed by computing the strength of the hydrogen-bond in a model imine derived from $p$-formylbenzoic acid and $N$-ethylalaninamide, $6 \mathbf{a}$.

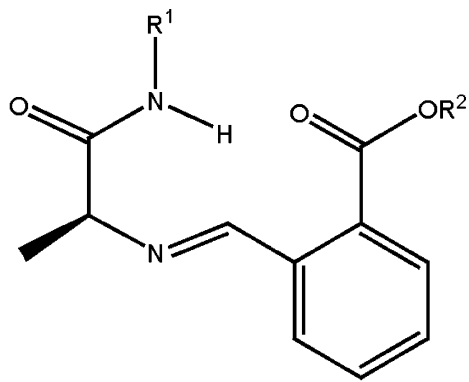

6a $\mathrm{R}^{1}=$-Et, $\mathrm{R}^{2}=-\mathrm{H} ; \quad$ 7a $\mathrm{R}^{1}=-\left(\mathrm{CH}_{2}\right)_{3} \mathrm{CHMeNHMe}, \mathrm{R}^{2}=-\mathrm{H}$ 6b $\mathrm{R}^{1}=-\mathrm{Et}, \mathrm{R}^{2}=-\mathrm{Me} ; 7 \mathbf{b} \mathrm{R}^{1}=-\left(\mathrm{CH}_{2}\right)_{3} \mathrm{CHMeNHMe}, \mathrm{R}^{2}=-\mathrm{Me}$

The B3LYP/6-31G* computed enthalpic difference for the compact and open structures of $\mathbf{6 a}$, which are depicted in Figure 2 , panels a and $\mathrm{b}$, respectively, is $-6.8 \mathrm{~kJ} / \mathrm{mol}$, which shows that the interaction between the $\mathrm{C}=\mathrm{O}$ oxygen atom of the $o-\mathrm{CO}_{2} \mathrm{H}$ substituent and the amide hydrogen is not the complete answer for the experimental observations. Therefore, this seems to indicate that at least one of the remaining two hydrogenbonds shown in Figure 1a is also important for the global stabilization of the compact inward structure.

A second model, 7a, of the same imine intermediate, $\mathbf{4 o}$, was thus considered, where the 8 -aminoquinoline ring has been purposely removed. In the latter model, the $\mathrm{C}=\mathrm{O}$ oxygen atom of the $o-\mathrm{CO}_{2} \mathrm{H}$ substituent can establish intramolecular hydrogenbonds with hydrogens from both the amide and the amino groups. In fact, as illustrated in Figure 3, two situations are possible: (1) a single $(\mathrm{O} \cdots \mathrm{H}-\mathrm{N})$ hydrogen-bond in an inward configuration, Figure $3 \mathrm{a}$, with the $\mathrm{C}=\mathrm{O}$ interacting with the 
TABLE 1. B3LYP/6-31G* Selected Bond Lengths and Relative Stability of Inward and Outward Structures of the Imine Intermediates $^{a, b}$

\begin{tabular}{|c|c|c|c|c|}
\hline compound & $\mathrm{X}^{a}$ & $\begin{array}{c}\text { distance of } \\
(\mathrm{N}-\mathrm{C}) / \\
\AA \text { inward/ } \\
\text { outward }\end{array}$ & $\begin{array}{l}\text { distance of } \\
\mathrm{X} \cdots \mathrm{H}-\mathrm{N} / \\
\AA \text { inward }\end{array}$ & $\begin{array}{c}\text { relative } \\
\text { stability of } \\
\text { the inward/ } \\
\text { outward } \\
\text { structures }^{d}\end{array}$ \\
\hline benzaldehyde & $\mathrm{H}$ & 3.779 & 6.938 & \\
\hline $4 d$ & $o$-COOMe & $\mathbf{3 . 2 7 6} / 3.757$ & 2.726 & $-3.2(-3.2)$ \\
\hline $4 e$ & $o$-OMe & $3.742 / 3.757$ & 5.160 & $10.1(10.8)$ \\
\hline $4 f$ & $o-\mathrm{OH}$ & $3.616 / 3.706$ & 3.515 & $28.7(29.1)$ \\
\hline $4 \mathrm{~g}$ & $\mathrm{O}-\mathrm{CF}_{3}$ & $3.779 / 3.773$ & 4.104 & $8.6(9.3)$ \\
\hline $4 \mathrm{~h}$ & $o-\mathrm{Me}$ & $3.801 / 3.760$ & 7.101 & $1.5(1.7)$ \\
\hline $4 i$ & $o-\mathrm{NO}_{2}$ & $3.338 / 3.779$ & 4.496 & $7.1(7.6)$ \\
\hline $4 \mathbf{j}$ & $o-\mathrm{CH}_{2} \mathrm{OH}$ & $3.579^{e}$ & 7.444 & \\
\hline $4 k$ & $o-\mathrm{CH}_{2} \mathrm{NH}_{2}$ & $3.155 / 3.777$ & 3.038 & $33.1(32.9)$ \\
\hline 41 & $o$-COMe & $\mathbf{3 . 4 2 4} / 3.761$ & 2.310 & $-3.8(-3.5)$ \\
\hline $4 m$ & $o$-CSMe & $3.687 / 3.758$ & 3.552 & $-0.1(0.05)$ \\
\hline $4 n$ & $o$-CSOMe & $3.693 / 3.751$ & 3.539 & $0.2(0.6)$ \\
\hline 40 & $o-\mathrm{COOH}$ & $\mathbf{3 . 2 3 4} / 3.760$ & 2.186 & $-35.4(-34.2)$ \\
\hline
\end{tabular}

${ }^{a}$ In compounds $4 .{ }^{b}$ The inward configuration is that with the $\mathrm{X}$ group pointing toward the primaquine amino group, and outward means a configuration with the $\mathrm{X}$ group pointing in the opposite direction. ${ }^{c}$ The distance between the hydrogen atom of primary amino group of the primaquine's lateral chain and the oxygen or nitrogen atoms of the $\mathrm{X}$ group, except when $\mathrm{X}=\mathrm{CH}_{3}$ for which the $\mathrm{C}$ atom was considered. ${ }^{d}$ Positive enthalpic values (in $\mathrm{kJ} / \mathrm{mol}$ and at $T=298.15 \mathrm{~K}$ ) mean that the outward conformation is more stable. Energies at $T=0 \mathrm{~K}$ are given in parenthesis. ${ }^{e}$ No outward structure was found due to the formation of a strong $\mathrm{O}-\mathrm{H} \cdots \mathrm{N}_{3}$ interaction, $\mathrm{d}(\mathrm{H}-\mathrm{N})=1.866 \AA$, which keeps the $\mathrm{O}-\mathrm{H}$ group pointing inward of the primaquine's side chain.

amine hydrogen, and (2) a doubly hydrogen-bonded inward configuration, Figure $3 b$, with the $\mathrm{C}=\mathrm{O}$ group interacting with the amide hydrogen $(\mathrm{O} \cdots \mathrm{H}-\mathrm{N}$ bond $)$ and the carboxyl $\mathrm{O}-\mathrm{H}$ group interacting with the amine nitrogen $(\mathrm{O}-\mathrm{H} \cdots \mathrm{N}$ bond $)$.

The enthalpic difference between the structures shown in Figures $3 \mathrm{a}$ and 4 (7a in an inward and an outward conformation, respectively), regarding the opening of the structure with only one hydrogen-bond interaction, is $2.7 \mathrm{~kJ} / \mathrm{mol}$. This result suggests that this interaction stabilizes the inward configuration more efficiently than that which occurs between the $\mathrm{C}=\mathrm{O}$ bond and the amino group, as in the case of the model 6a. This small enthalpic difference implies that a single hydrogen-bond interaction is not sufficient for the large observed stabilization of the inward conformation with respect to the outward conformation of compound 4o. However, it does seem that those are key interactions in inducing a compact structure in the imine intermediate, in approaching the $\mathrm{N}$ and $\mathrm{C}$ atoms involved in ring-closure, and in directing the I-2 and I-5 hydrogen atoms toward the same side relative to the plane of the imidazolidin4-one ring. In the case of the structure depicted in Figure 3b, where two intramolecular hydrogen-bonds are now formed, the enthalpic difference between the outward and the inward conformations is now $35.0 \mathrm{~kJ} / \mathrm{mol}$. This value is similar to that computed for the full imine intermediate (Figure 1), which shows that the double interaction is relevant to the stabilization of the intermediate compact folding. These findings support NMR data for compound 5c. This is the structural interpretation displayed in Scheme 3B, which suggests a highly compact structure that seems to be possible when the $\mathrm{X}$ group (Scheme 1) contains a $\mathrm{C}=\mathrm{O}$ bond that points toward the primaquine moiety.

Likewise, for the $\mathbf{6 b}$ and $\mathbf{7 b}$ models, the computed enthalpic differences between the compact and the open structures of $\mathbf{6 b}$ and $7 \mathbf{b}$ are -6.3 and $3.6 \mathrm{~kJ} / \mathrm{mol}$, respectively. These differences
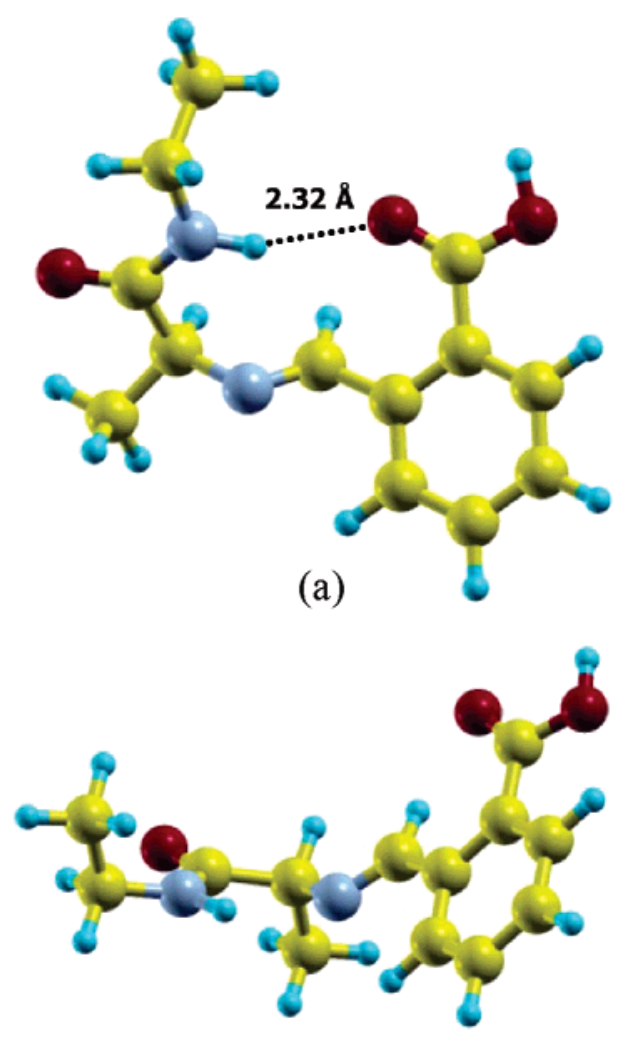

(b)

FIGURE 2. Compact inward (a) and open outward (b) structures for compound $\mathbf{6 a}$.

are almost identical to those reported above for compounds $\mathbf{6 a}$ and 7a when a single internal hydrogen interaction is present.

The enthalpic differences between the inward and the outward structures are low but seem to be sufficient for the stabilization of inward structures in compounds $\mathbf{4}$ containing an $\mathrm{X}$ group with a $\mathrm{C}=\mathrm{O}$ bond, which are the starting geometries for the reaction that leads to ring-closure. In fact, when $\mathrm{C}=\mathrm{O}$ is present, $\mathrm{N}-\mathrm{C}$ distances are small, and the geometry highly favors the subsequent ring-closure. When $\mathrm{C}=\mathrm{O}$ is absent, the favorable $\mathrm{C}=\mathrm{O} \cdots \mathrm{H}-\mathrm{N}$ interactions are not possible, and stereoselective reactions do not take place. Further, the energetic difference between the inward and the outward structures is not the reflex of the $\mathrm{C}=\mathrm{O} \cdots \mathrm{H}-\mathrm{N}$ hydrogen-bond strength alone; it is the balance between the energetic gain from the establishment of that hydrogen-bond and the energetic loss from the increased strain, which leads to an overall stabilization effect on the inward structure at the expense of the outward one.

As stated above, to accomplish the objectives of the present work, we have undertaken a detailed computational study on the energetic and structural properties of compounds $\mathbf{4}$ derived from different $o$-R-benzaldeydes $(\mathrm{R}=-\mathrm{H} ;-\mathrm{Me} ;-\mathrm{OH}$; $-\mathrm{COOMe} ;-\mathrm{CF}_{3} ;-\mathrm{NO}_{2} ;-\mathrm{CH}_{2} \mathrm{NH}_{2} ;-\mathrm{CH}_{2} \mathrm{OH} ;-\mathrm{COMe}$; $-\mathrm{CSMe}$; and $-\mathrm{CSOMe}$ ). These groups have been chosen to cover several possibilities for the interactions between them and $\mathrm{N}-\mathrm{H}$ groups in the $\mathrm{N}$-alanilprimaquine moiety. A summary of the most important geometric and energetic results that were obtained for both the inward and the outward conformations of compounds $\mathbf{4}$ is presented in Table 1 . The relative stabilities of the inward and the outward structures for $\mathbf{4}$ clearly show that there is a preference for the inward conformation only when $\mathrm{X}$ 

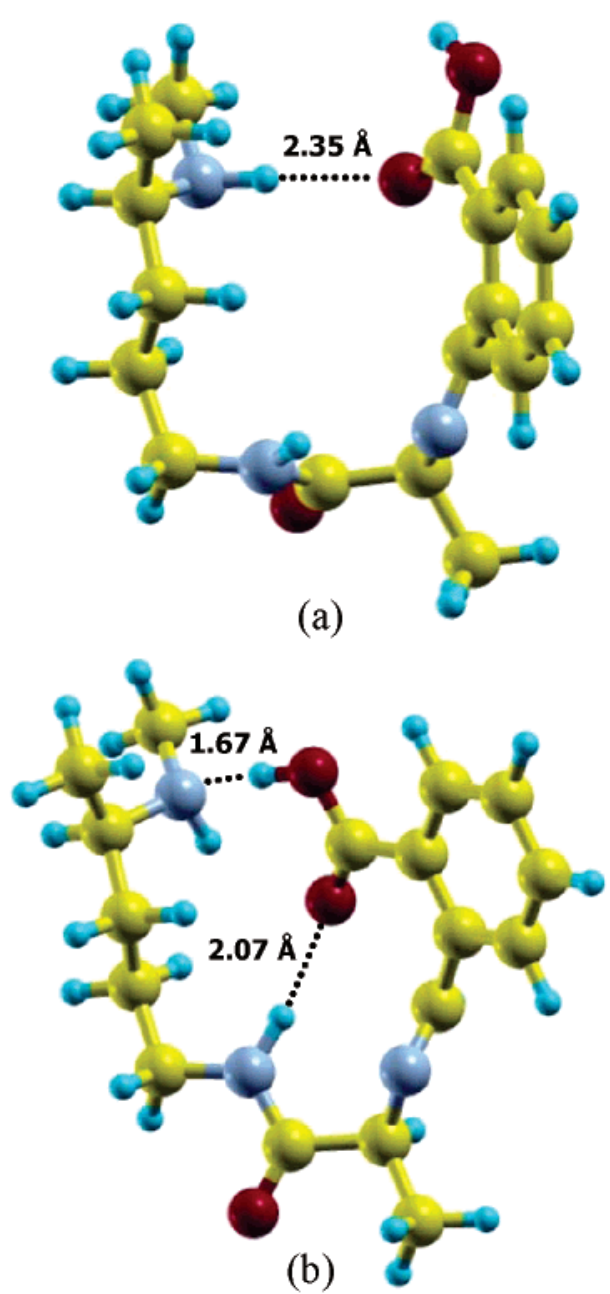

FIGURE 3. Compact inward structures for the medium-sized model 7a with one (a) and two (b) internal hydrogen-bonds.

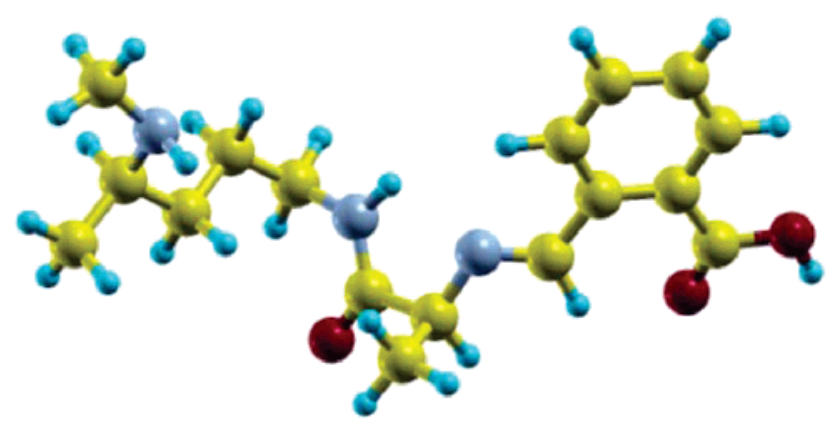

FIGURE 4. Open outward structure for the medium-sized model 7a.

is $-\mathrm{COOH}$. Similar to that written above for the smaller models, the analysis of the geometric data for this imine intermediate shows that the packing of the inward structure produces short $\mathrm{N}-\mathrm{C}$ and $\mathrm{X} \cdot \cdot \mathrm{H}-\mathrm{N}$ distances (cf. Table 1 ) that seem to be the justification for a stereoselective closure of the imidazolidin4-one ring. Accordingly, the full analysis of Table 1 suggests that stereoselective imidazolidin-4-one formation will only occur from imine intermediates derived from benzaldehydes bearing a $\mathrm{C}=\mathrm{O}$ group in the ortho position, for example, imines $\mathbf{4 d}, \mathbf{4} \mathbf{l}$, and 4o, as these imines are the only ones that present a more
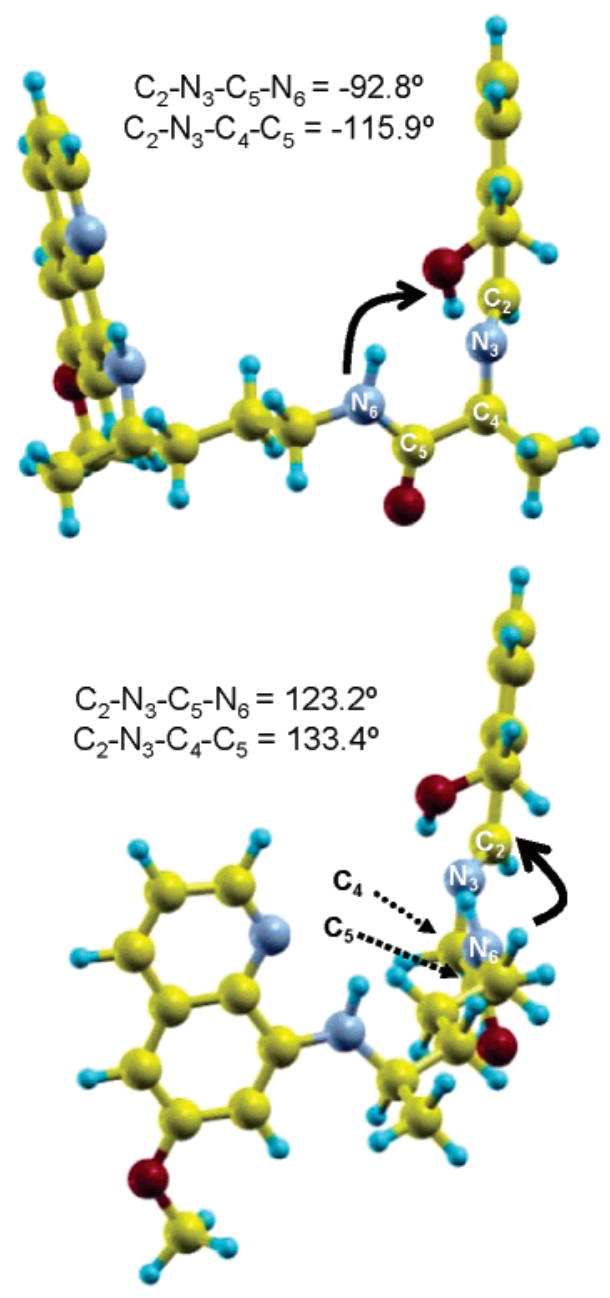

FIGURE 5. Degenerate inward but open optimized structures for compound $\mathbf{4 j}$, stabilized by internal $\mathrm{O}-\mathrm{H} \cdots \mathrm{N}$ hydrogen-bonds. The directions for the possible $\mathrm{N}-\mathrm{-}-\mathrm{C}$ closing are illustrated with black arrows, and selected dihedral angles are also indicated.

stable inward than outward conformation with short $\mathrm{N}-\mathrm{C}$ and $\mathrm{X} \cdots \mathrm{H}-\mathrm{N}$ distances. For example, short $\mathrm{N}-\mathrm{C}$ and $\mathrm{X} \cdots \mathrm{H}-\mathrm{N}$ distances are calculated for the inward conformation of $\mathbf{4 k}$, but because this conformation is much more unstable than the outward (open) conformation, ring-closure is not expected to be stereoselective in this case.

Although these are gas-phase calculations, it is reasonable to consider that, for the open (outward) conformations, ringclosure would require about the same amount of energy whether the amide nitrogen approaches the imine carbon from one face or the other, which gives rise to the formation of both possible isomers of $\mathbf{5}$. The absence of intramolecular hydrogen-bonding enables an almost free rotation around the $\mathrm{N}-\mathrm{C}$ bond, compare I-3 and I-4 atoms in Scheme 1.

In the case of the imine intermediate $4 \mathbf{h}, \mathrm{X}=-\mathrm{CH}_{3}$, where intramolecular hydrogen-bonding involving the benzaldehyde substituent (X) cannot take place, the energetic difference between the inward and the outward conformations is quite low. This supports the suggestions that the internal hydrogen-bonding stabilizes a single preferred and compact structure, which allows for a stereoselective cyclization. In the cases where there is no observed preference for a compact structure, in principle, rotation around the bond connecting I- 3 and I-4 atoms in one 
or in the opposite direction would have an identical energetic cost, and thus stereoselectivity is not expected. Stereoselectivity is also not expected for compound $\mathbf{4 j}$, because internal hydrogenbonding is not followed by structure compacting, which is in contrast to what was found for compounds where $\mathrm{X}$ has a $\mathrm{C}=\mathrm{O}$ group. Indeed, two degenerate structures are found for compound $\mathbf{4 j}$, where the amide $\mathrm{N}-\mathrm{H}$ adopts two different directions with respect to the $\mathrm{X}=-\mathrm{CH}_{2} \mathrm{OH}$ group, as depicted in Figure 5. Further, the difference between both conformations is only $1.4 \mathrm{~kJ} / \mathrm{mol}$.

\section{Final Considerations}

The present work reports an unanticipated diastereoselectivity of imidazolidin-4-one formation from the reaction between primaquine $\alpha$-aminoamides and benzaldehydes that bear a carbonyl substituent in the ortho position. Unlike other works, where stereoselectivity was seen to be substituent-dependent in the sense that it correlated with either size, configuration, or electronic properties of the substituents, ${ }^{21-23}$ the present findings point to a specific set of conditions that gives rise to the observed diastereoselectivities.

An unanticipated diastereoselectivity in the catalytic asymmetric Staudinger reactions has been recently reported by $\mathrm{Fu}$ and co-workers ${ }^{24}$ and has been further explored by $\mathrm{Xu}$ and coworkers. ${ }^{25}$ These authors were able to establish that the relative stereoselectivity of $\beta$-lactam formation is determined by the competition between direct ring-closure (to yield the $c i s-\beta$ lactam) and isomerization of the imine moiety prior to ringclosure (which leads to the trans- $\beta$-lactam). Further, these authors observed that the stereoelectronic properties of both the imine and the ketene substituents are correlated with the rate of ring-closure; therefore, these properties directly affect the final $\beta$-lactam cis/trans ratio. In our particular case, varying substituent-dependent cis/trans ratios are not observed for the configuration of the imidazolidin-4-one ring. What we actually have is an "all-or-none" situation, where $100 \%$ stereoselectivity is observed if, and only if, an ortho-carbonyl group is present in the aldehyde moiety; otherwise, stereoselectivity simply does not take place.

Other studies on stereoselective intramolecular cyclizations have been recently published, such as the work of Clemente and Houk which was devoted to the computational studies of intramolecular aldol cyclizations catalyzed by amino acids; ${ }^{26}$ these studies provide deeper insight into the origin of the stereoselectivities observed for those reactions, which were found to be governed by both the amino acid catalyst and the substrate substituent. Another very recent work is the DFT study by Thiel and co-workers ${ }^{27}$ on the enantioselectivity of $\alpha$-alkylation of aldehydes that are catalyzed by 2 -methylproline. Thiel and co-workers have analyzed the reaction mechanism and have found that the relevant step was an intramolecular nucleophilic substitution. This involved the formation of an enamine intermediate, where the added base (triethylamine) was not only responsible for accelerating the reaction through electrostatic

(21) Yajima, T.; Okada, K.; Nagano, H. Tetrahedron 2004, 60, 5683.

(22) Nagano, H.; Ohkouchi, H.; Yajima, T. Tetrahedron 2003, 59, 3649

(23) Freccero, M.; Gandolfi, R.; Sarzi-Amadè, M. Tetrahedron 1999, 55,11309 .

(24) Lee, E. C.; Hodous, B. L.; Bergin, E.; Shih, C.; Fu, G. C. J. Am. Chem. Soc. 2005, 127, 11586.

(25) Jiao, L.; Liang, Y.; Xu, J. J. Am. Chem. Soc. 2006, 128, 6060.

(26) Clemente, F. R.; Houk, K. N. J. Am. Chem. Soc. 2005, 127, 11294

(27) Fu, A.; List, B.; Thiel, W. J. Org. Chem. 2006, 71, 320. activation of the leaving group but also modulated the stereoselectivity of the process by stabilizing the syn and anti transition states to different extents.

Comparing these reports with the present work, our results seem to be an unique example where only a specific combination of two factors, namely, a carbonyl group adequately placed and the primaquine aliphatic nitrogens, gives rise to a stereoselective intramolecular cyclization. Katritzky et al. have previously reported the stereoselective synthesis of $1 H$-imidazo[2,1- $a$ ]isoindole-2,5 $(3 H, 9 \mathrm{~b} H)$-diones by reacting $o \mathrm{FbzOH}$ with different $N^{\alpha}$-Boc-protected $\alpha$-aminoamides that have been derived from $\alpha$-amino acids. In Katritzky's work, as in our case, the relevant step for stereoselectivity was the intramolecular nucleophilic attack of an amide nitrogen to an imine carbon, with the formation of the imidazolidin-4-one structure ${ }^{28}$ these authors obtained as the major product the isomer where the hydrogen atoms attached to the imidazolidin-4-one carbons 2 and 5 that were trans to each other, which is quite the opposite of our findings. In their case, stereoselectivity was ascribed to steric constraints between the amino acid side chain and the amide substituent. In our work, the amide substituent was always the same (i.e., the primaquine moiety), and stereoselectivity was not dependent on the amino acid component, as is shown by the results obtained for compounds $\mathbf{5 a}-\mathbf{c}$. Further, our diastereoselective cyclizations always led to the cis isomer relative to the positions of the imidazolidin-4-one's H-2 and H-5. Computational studies allowed us to determine the probable origin for our "ortho-carbonyl-dependent" stereoselectivity, which is the establishment of adequate intramolecular hydrogenbonds in the imine intermediate. These hydrogen-bonds stabilize a compactly folded conformation that brings closely together the two atoms involved in ring-closure: the amide nitrogen and the imine carbon. The quasi-cyclic conformation on the acyclic intermediate promptly promotes an oriented nucleophilic $\mathrm{N}_{\text {amide }}$ $\rightarrow \mathrm{C}_{\text {imine }}$ attack that yields the cis isomer as the exclusive cyclization product. As far as we are aware, this is the first time that such a specific control of stereoselectivity in imidazolidin-4-one synthesis has been reported. García-Martínez et al. have reported an X-ray and NMR configurational analysis of 1,3-imidazolidin-4-ones derived from $(-)$ - $(S)$-phenylethylamine and have also found the existence of intramolecular hydrogen-bonds that are capable of controlling the conformation of the phenethyl and acyl groups in the solid state as well as in solution. ${ }^{29}$ Although this work does not exactly concern the same phenomena we are now reporting, it does outline the relevance of intramolecular hydrogen-bonds in the conformational properties of similar compounds.

\section{Experimental Methods}

Synthesis. Compounds $\mathbf{5 a}-\mathbf{c}$ and $\mathbf{5 e}-\mathbf{j}$ were synthesized as previously described (Scheme 1). ${ }^{5}$ Reaction progress was monitored by TLC. Crude mixtures were purified by column chromatography on silica and were eluted with mixtures of dichloromethane and tetrahydrofuran. Chromatographically identical fractions were pooled and often re-columned. Final fractions with the correct molecular weights as determined by high-resolution MALDI-TOF mass spectrometry were analyzed by ${ }^{1} \mathrm{H}-$ and ${ }^{13} \mathrm{C}$ NMR, and the corresponding spectroscopic data are given as Supporting Informa-

(28) Katritzky, A. R.; Xu, Y.-J.; He, H.-Y.; Steel, P. J. J. Chem. Soc. Perkin Trans. 1 2001, 1767.

(29) García-Martínez, C.; Cervantes-Cuevas, H.; Escalante-García, J. Chirality 2003, 15, S74. 
tion. The synthesis of $\mathbf{5 j}$ yielded a complex reaction mixture from which the complete isolation of the target product was not achieved; nonetheless, fractions enriched in $\mathbf{5 j}$ were obtained and analyzed. Further, 2D-NMR homonuclear (COSY, TOCSY, and NOESY) and heteronuclear (HMBC and HSQC) correlation experiments with compounds $\mathbf{5 b}$ and $\mathbf{5 c}$ in deuterated chloroform $\left(\mathrm{CDCl}_{3}\right)$ were carried out.

Computational Details. The semiempirical AM1 method, as included in the Gaussian 98 suite of programs, ${ }^{30}$ was initially employed to select the most stable geometries for the imine intermediates $\mathbf{4 d}-\mathbf{o}$ that have the $\mathrm{X}$ substituent oriented either

(30) Frisch, M. J.; Trucks, G. W.; Schlegel, H. B.; Scuseria, G. E.; Robb, M. A.; Cheeseman, J. R.; Zakrzewski, V. G.; Montgomery, J. A., Jr.; Stratmann, R. E.; Burant, J. C.; Dapprich, S.; Millan, J. M.; Daniels, A. D.; Kudin, K. N.; Strain, M. C.; Farkas, O.; Tomasi, J.; Barone, V.; Cossi, M.; Cammi, R.; Mennucci, B.; Pomelli, C.; Adammo, C.; Clifford, S.; Ochterski, J.; Petersson, G. A.; Ayala, P. Y.; Cui, G.; Morokuma, K.; Malick, D. K.; Rabuck, A. D.; Raghavachari, K.; Foresman, J. B.; Cioslowski, J.; Ortiz, J. V.; Stefanov, B. B.; Liu, G.; Liashenko, A.; Piskorz, P.; Komaromi, I.; Gomperts, R.; Martin, R. L.; Fox, D. J.; Keith, T.; Al-Laham, M. A.; Peng, C. Y.; Nanayakkara, A.; Gonzalez, C.; Challacombe, M.; Gill, P. M. W.; Johnson, B.; Chen, W.; Wong, M. W.; Andres, J. L.; Head-Gordon, M.; Replogle, E. S.; Pople, J. A. Gaussian 98, Rev. A.3,;Gaussian, Inc.: Pittsburgh PA, 1998.

(31) Becke, A. D. J. Chem. Phys. 1993, 98, 5648. toward the primaquine moiety (similar to that in Figure 1 and named "inward" structure) or away from it (named "outward" structure). Several different starting geometries were considered to ensure that a minimum on the PES was reached for both the inward and the outward structures. For each minimized structure, further full geometry optimization was carried out at the B3LYP/6-31G* level, and the structures have been characterized as true minima on the potential energy surface after the calculation of frequencies at the same DFT level. ${ }^{31}$ More details are given in the Supporting Information.

Acknowledgment. The authors thank Fundação para a Ciência e Tecnologia (FCT, Portugal) for financial support to research units CIQUP and CECF through plurianual funding and also through project POCTI/FCB/39218/2001. J.R.B.G. thanks FCT for his postdoctoral research grant SFRH/BPD/ $24676 / 2005$.

Supporting Information Available: General synthetic procedures, compound spectroscopic data, and B3LYP/6-31G* optimized structures (in Cartesian coordinates in $\AA$ ) for all imine intermediates. This material is available free of charge via the Internet at http://pubs.acs.org.

JO0703202 